\title{
$\beta$-endorphin modulates the effect of stress on novelty-suppressed feeding
}

\author{
Elizabeth T. Barfield ${ }^{1}$, V. Alexandra Moser ${ }^{1,2}$, Annie Hand ${ }^{1}$ and Judith E. Grisel ${ }^{1,3 *}$ \\ ${ }^{1}$ Department of Neuroscience, Furman University, Greenville, SC, USA \\ ${ }^{2}$ Neuroscience Graduate Program, University of Southern California, Los Angeles, CA, USA \\ ${ }^{3}$ Department of Psychology, Bucknell University, Lewisburg, PA, USA
}

Edited by:

Michael V. Baratta, University of

Colorado Boulder, USA

Reviewed by:

Osborne F. Almeida, Max Planck

Institute of Psychiatry, Germany

Ben N. Greenwood, University of

Colorado Boulder, USA

John P. Christianson, University of

Colorado Boulder, USA

*Correspondence:

Judith E. Grisel, Department of

Psychology, Bucknell University,

One Dent Drive, Lewisburg,

PA 17837, USA.

e-mail: j.grisel@bucknell.edu
Although stress is implicated in the pathophysiology of mood and anxiety disorders, not all individuals who suffer stressful life events develop psychopathology. Differential susceptibility to stress may be influenced by genetically mediated differences in hypothalamic-pituitary-adrenal (HPA) axis activity and moderation of the stress response by the opioid peptide $\beta$-endorphin ( $\beta$-E). The present study investigated genetic contributions to coping behavior by examining anxious behavior of transgenic mice with varying capacities to synthesize $\beta$-E $\left[\mathrm{B} 6.129 \mathrm{~S} 2-\mathrm{Pomc}^{\text {tm1 }} \mathrm{Low} / \mathrm{J}\right.$; regulated by insertion of a premature stop codon into one or both copies of the proopiomelanocortin (POMC) gene], both under normal conditions and following $3 \mathrm{~min}$ of forced swim (FS). Ten minutes after this stress exposure or a control manipulation, acutely food-deprived female and male transgenic mice were subjected to a novelty-suppressed feeding (NSF) test, during which their interaction with an almond slice located in the center of an open field box was measured. There was an interaction between genotype and stress for latency to approach the almond and whether or not the almond was approached, such that mice with low or absent $\beta$-E displayed a stronger aversion to novelty-feeding after stress exposure than did mice with normal levels. These data provide evidence for a moderating effect of $\beta-E$ on the behavioral response to stress. Genotypic differences in anxious behavior emerged when mice were stressed prior to behavioral assessment, suggesting that $\beta$-E plays a role in coping behavior. These findings indicate that genetic variability in sensitivity of the $\beta-E$ system to stress may contribute, at least in part, to heritable differences in stress reactivity as well as vulnerability to stress-related psychopathology.

Keywords: opioids, transgenic, anxiety, depression, mice, hyponeophagia, novelty

\section{INTRODUCTION}

Over the past few decades, an extensive body of work has emerged linking vulnerability to affective and anxiety disorders with stressful life events. Stressful events often precipitate depressive episodes (Brown et al., 1987; Hammen et al., 1992), and early life stress has been shown to increase the risk for stressrelated psychiatric disorders in adulthood (Kendler et al., 1992a; McEwen, 2003). However, not all individuals who suffer stressful life events develop psychopathology; evidence suggests that some individuals are resistant, and others vulnerable, to the adverse effects of stress (de Rijk and de Kloet, 2005; Southwick et al., 2005; Stiller et al., 2011; Castro et al., 2012; see Sandi and RichterLevin, 2009, for review). Differential vulnerability to stress is regulated by an interaction of genetic and developmental factors with major life stressors (Sullivan et al., 2000; Danese, 2008; Bet et al., 2009). However, the neurobiological mechanisms underlying susceptibility to stress-related disorders remains poorly understood.

One hypothesis is that genetic factors influence coping style to moderate the vulnerability to stress (see Feder et al., 2009, for review). "Coping" describes the behavioral and physiological mechanisms that occur to return an organism to a basal state following stress exposure. Thus, less effective coping, defined as a failure to recover to a baseline state after stress exposure, may render an individual more susceptible to stress-induced psychopathology (McEwen, 2002; Meng et al., 2011). For example, in rats, a behavioral profile characterized by high anxiety is associated with susceptibility to the development of stress-induced depression-like behavior (Sandi et al., 2008; Stedenfeld et al., 2011; Castro et al., 2012). In humans, the neuroticism-anxiety trait, which is associated with disengagement coping (an ineffective strategy; see Carver and Connor-Smith, 2010 for a review of personality and coping) and less flexible coping strategies across situations (Lee-Bagley et al., 2005), strongly reflects liability to major depressive disorder (MDD) and generalized anxiety disorder (GAD; Kendler et al., 2006a, 2007).

Moreover, differences in coping behavior and vulnerability to stress may have a biological basis in hypothalamicpituitary-adrenal (HPA) axis function (van Santen et al., 2011) and the moderating effects of the endogenous opioid peptide $\beta$-endorphin $(\beta-\mathrm{E})$ on the stress response (Schedlowski et al., 1995; Gianoulakis, 1998; Sarkar et al., 2007; Grisel et al., 2008; 
Barfield et al., 2010). Activation of the HPA axis following exposure to stressful stimuli mediates an adaptive response through a hormonal cascade of behavioral and physiological changes aimed at the maintenance of homeostasis in the body (Low, 2004). During stress, the secretion of corticotrophin releasing hormone $(\mathrm{CRH})$ stimulates expression of the proopiomelanocortin $(P O M C)$ gene in the anterior pituitary, which is subsequently translated into peptides such as adrenocorticotropic hormone (ACTH) and $\beta$-E (Charmandari et al., 2005). While ACTH activates the adrenal gland to initiate the peripheral response to stress, $\beta$-E attenuates the stress response, at least in part, by inhibiting secretion of CRH (Buckingham, 1986; Plotsky, 1991) and blocking stress-induced nociception (Bodnar et al., 1980; Nakagawasai et al., 1999; Parikh et al., 2011). Reports indicating modulation of the HPA axis by $\beta$-E fit well with those evincing a role for $\beta$ $\mathrm{E}$ in the behavioral response to stress (Amir, 1982; Yamada and Nabeshima, 1995; Ribeiro et al., 2005; Grisel et al., 2008; Barfield et al., 2010). For example, we have shown that transgenic mice with low $\beta$-E exhibit increased anxious behavior and show deficits in coping ability during an inescapable aversive situation (Grisel et al., 2008; Barfield et al., 2010). Thus, because stress-induced release of $\beta$-E mediates endocrine and behavioral responses that contribute to allostasis of the stress response, insufficient attenuation of the HPA axis arising from low $\beta$-E may contribute to maladaptive coping behavior under stressful conditions.

Here, we examined the role of $\beta-\mathrm{E}$ in anxious behavior of mice, both under basal conditions and following exposure to an acute stressor. Anxious behavior was assessed using the novelty-suppressed feeding (NSF) test, an ethologically relevant paradigm that measures the suppression of food intake (in a food-deprived animal) caused by exposure to a potentially anxiogenic novel environment (typically an open field; Merali et al., 2003; see Cryan and Sweeney, 2011 for summary of hyponeophagia paradigms). Because anxiolytics and chronic but not acute antidepressants reduce hyponeophagia (Britton and Britton, 1981; Shephard et al., 1985; Bodnoff et al., 1988; Bessa et al., 2009), the NSF test provides a sensitive and reliable measure of anxiety-related states in animals that resemble those in humans (Merali et al., 2003). Thus, we assessed the effect of genotype $(\beta-\mathrm{E}$ level) and previous stress exposure, as well as their interaction, on anxious behavior in the NSF test. We hypothesized that studying the behavioral response to stress in mice with varying levels of $\beta$-E would reveal an interaction of genetic predisposition and environmental stress, such that differences in coping behavior between genotypes would emerge following stress exposure.

\section{MATERIALS AND METHODS \\ SUBJECTS AND DESIGN}

Subjects were adult naïve male and female wild-type (C57BL/6J; B6), heterozygous (HT), and $\beta$-E-deficient (B6.129S2Pomc $^{\text {tm } 1 \text { Low }} / \mathrm{J}$; KO) mice. Transgenic mice were developed over a decade ago in the laboratory of Malcolm Low (Rubinstein et al., 1996) by insertion of a premature stop codon into the Pomc gene. Homozygotes $(\mathrm{KO})$ are entirely unable to synthesize $\beta$-E, though all other Pomc products show normal expression. Opioid receptor expression also remains unchanged (Rubinstein et al., 1996). Mice for these studies were bred in-house from stock purchased from Jackson Laboratories (Bar Harbor, ME, USA). The gene mutation has been fully backcrossed to the C57BL/6J strain (>20 generations). HT mice were bred from KO males and B6 females; others were bred under identical conditions from genotype-matched pairs. Mice were weaned at 21 days of age and were group-housed by sex with 3-4 per Plexiglas cage, measuring $20 \times 35 \times 14.5 \mathrm{~cm}$. Mice were maintained in a colony room at $21 \pm 2{ }^{\circ} \mathrm{C}$, on a reverse 12:12 light:dark cycle with lights on at 7 p.m. Water and food were available ad libitum. All procedures were carried out in accordance with the National Institutes of Health guidelines and approved by the Animal Care and Use Committee of Furman University.

\section{BEHAVIORAL TESTING}

On testing day, food was removed at $\sim 8$ a.m., 1 h after lights-out, in order to facilitate feeding (LeSauter et al., 2009). Behavioral testing occurred during the animals' active phase, between 10 a.m. and 4 p.m., in a dimly lit testing room, so as to enable behavioral assessment of genotypic differences (Branchi and Ricceri, 2002; Hossain et al., 2004; Roedel et al., 2006). Mice were brought into the testing area, weighed, tail marked, and randomly assigned to the control or the forced swim (FS) condition.

Mice in the control condition were individually placed in a Plexiglas cage in the testing room for a 10 min habituation period. Mice in the FS condition were subject to a modified version of Porsolt et al.'s (1977) FS Test for $3 \mathrm{~min}$ in a white plastic 5 gallon bucket measuring $30 \mathrm{~cm}$ in diameter by $40 \mathrm{~cm}$ in height containing $20 \mathrm{~cm}$ of water maintained at $23^{\circ} \mathrm{C}$. To minimize the possibility of confounding effects (e.g., fatigue) from sex and genotypic differences in behavior (previously reported for $15 \mathrm{~min}$ of FS exposure, Barfield et al., 2010), pilot testing was conducted to determine a FS duration that would induce subthreshold amounts of stress. Duration of $3 \mathrm{~min}$ was chosen because no sex or genotypic differences in immobile behavior emerged following this brief length of time. Mice were judged immobile when making no movements other than those required to stay afloat, for at least $5 \mathrm{~s}$. Two independent observers recorded latency to immobility, total time spent immobile, and number of immobile segments. Following the FS, mice were individually placed in a Plexiglas cage in the testing room for a $7 \mathrm{~min}$ habituation period.

After habituation in the testing room, mice from both the control and the FS conditions were subject to the NSF test (Britton and Britton, 1981; Bodnoff et al., 1988). Mice were individually placed in an open field box $(100 \times 100 \times 4.5 \mathrm{~cm})$ that contained a pre-weighed almond slice in the center, for $5 \mathrm{~min}$. Two independent observers recorded whether the almond was approached, the latency to approach the almond, and the number of times that the mouse sniffed the almond. Following the NSF test, the almond slice was weighed, and the amount of almond eaten was recorded.

\section{STATISTICAL ANALYSIS}

Main effects of and interactions between genotype (B6, HT, KO), sex, and stress condition (control, FST) were analyzed using between-subjects analysis of variance (ANOVA). Significant main effects and interactions were further examined using Fisher's 
least significant difference (LSD) test. Three separate Two-Way chi-square tests of independence were performed to determine whether correlations existed between (1) approach behavior (whether or not the almond was approached) and stress condition $(2 \times 2$ design), $(2)$ approach behavior and genotype $(2 \times 3$ design), and (3) approach behavior and genotype with condition $(2 \times 6$ design). Statistical analyses were performed using SPSS Statistics 17.0 (SPSS, Inc., Chicago, IL). In all cases, the criterion for significance ( $\alpha$ level) was set at $p \leq 0.05$.

\section{RESULTS}

There were no main effects of or interactions with sex, so male and female data were collapsed for all analyses. As expected, there were no main effects of genotype on any measure of immobility in the 3 min FS exposure.

In terms of latency to approach the almond, there was a main effect of condition $\left[F_{(1,81)}=31.261, p<0.001\right]$ and a main effect of genotype $\left[F_{(2,80)}=9.696, p<0.001\right]$. Post-hoc analysis (Fisher's LSD) indicated that KOs took the longest to approach the almond $(p<0.01)$ and differed from both B6s and HTs, which did not differ from each other. There was also a significant interaction between genotype and condition for latency to approach the almond $\left[F_{(2,80)}=4.899, p \leq 0.01\right]$, such that the effect of stress on hyponeophagia increased as $\beta$-E levels decreased (Figure 1). There were no genotypic differences in the control condition, but in the stressed condition, KOs took the longest to approach the almond (as confirmed by Fisher's LSD, $p<0.05$ ). Thus, the main effect of genotype on latency to approach the almond was driven primarily by differences between genotypes in the stressed condition.

In terms of whether or not the almond was approached, FS exposure decreased the likelihood that mice would approach the almond at least once during the 5 -min NSF test $\left[X^{2}(1, N=83)=\right.$ $17.250, p<0.01]$. When data were collapsed across condition, whether the almond was approached depended on genotype

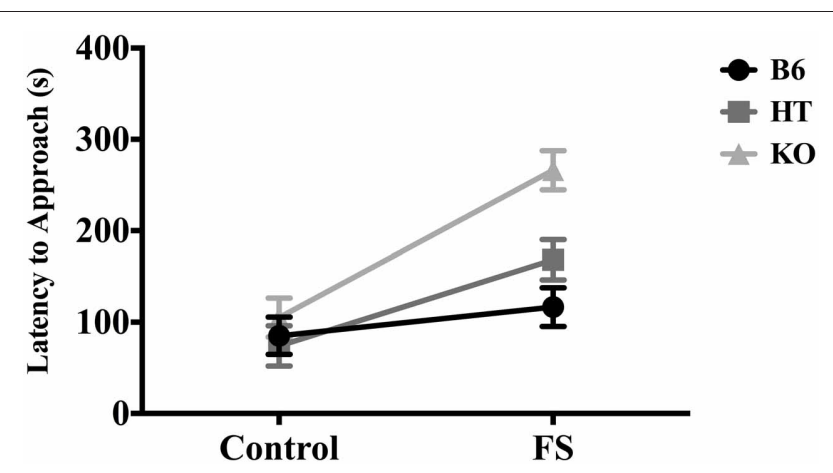

FIGURE 1 | Latency to approach almond slice during the 5-min novelty-suppressed feeding (NSF) test in wild-type C57BL/6J (B6), heterozygous (HT), and $\beta$-E knock-out (KO) mice, following either $\mathbf{1 0}$ min single housing (Control) or $\mathbf{3}$ min of forced swim, followed by $\mathbf{7}$ min single housing (FS). Data show mean \pm SE. Significant differences ( $p$-values $\leq 0.05$ ) between groups were determined following ANOVA by post-hoc analysis (Fisher's LSD test). There were main effects of the FS stressor, genotype, and an interaction between stress condition and genotype.
$\left[X^{2}(2, N=83)=15.235, p<0.01\right]$ such that as $\beta$-E levels decreased, likelihood of approaching the almond also decreased. To determine if genotype and condition were correlated with approach behavior, we further separated genotypes into groups based on condition (i.e., B6 stress, B6 control, HT stress, etc.). Whether or not the almond was approached depended on both genotype and condition $\left[X^{2}(5, N=83)=49.427, p<\right.$ 0.01]. Figure 2 depicts the percentages of mice in each genotype and condition that approached the almond. All control mice approached the almond, but whether or not stressed mice approached depended on genotype. Thus, the significant correlation between genotype (collapsed across condition) and whether the almond was approached was driven by genotypic differences that emerged only in the stressed condition.

For number of sniffs, there was a main effect of condition $\left[F_{(1,81)}=31.261, p<0.001\right]$ such that stressed mice sniffed the almond less frequently, and a main effect of genotype $\left[F_{(2,80)}=\right.$ 8.681, $p<0.001]$ such that $\beta$-E levels were indirectly correlated with degree of hyponeophagia (Figure 3). Post-hoc analysis indicated that B6s sniffed the almond more than either of the other two lines $(p \leq 0.001)$, but HTs and KOs did not differ from each other. There were no significant interaction effects of genotype and condition on number of sniffs $\left[F_{(2,80)}=2.043, p>0.05\right]$.

There was a main effect of condition on amount of almond eaten $\left[F_{(1,81)}=17.470, p<0.001\right]$ such that stressed mice ate less (Figure 4). However, there was no main effect of genotype $\left[F_{(2,80)}=0.107, p>0.05\right]$ nor an interaction between genotype and condition for this measure $\left[F_{(2,80)}=0.727, p>0.05\right]$.

\section{DISCUSSION}

Employing the NSF test to assess anxious behavior in transgenic mice expressing varying levels of $\beta$-E, our findings suggest that $\beta$-E modulates the effect of stress on behavior. The ability of exposure to a novel environment to suppress interaction with and ingestion of a highly palatable food was magnified when

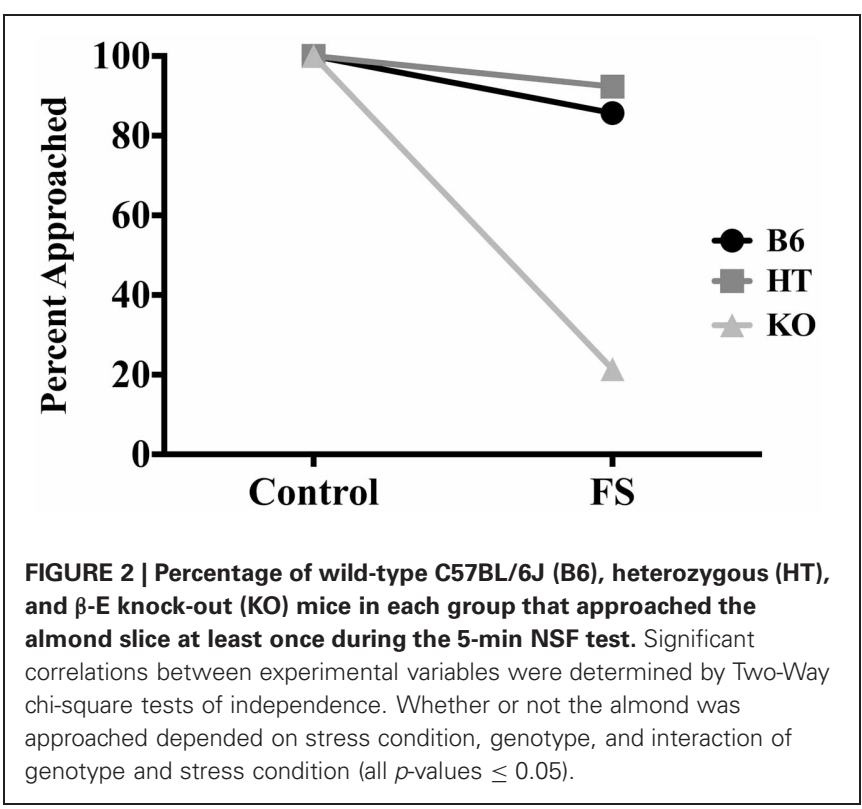




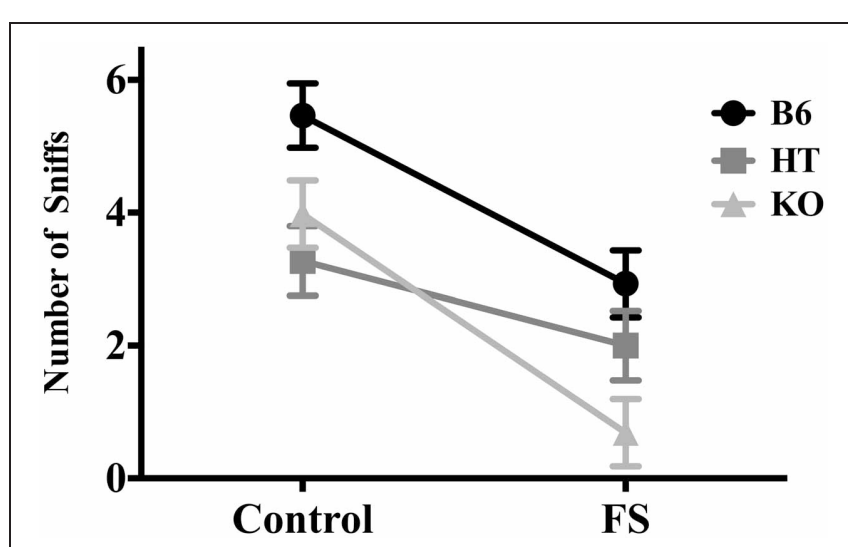

FIGURE 3 | Number of sniffs to the almond slice made by wild-type C57BL/6J (B6), heterozygous (HT), and $\beta$-E knock-out (KO) mice during the 5-min NSF test. Data show mean \pm SE. ANOVA and post-hoc analysis (Fisher's LSD test) indicated that forced swim exposure decreased almond sniffing, and a main effect of genotype reflected the fact that B6s sniffed the almond more than either of the other two lines, which did not differ from each other ( $p$-values $\leq 0.05$ ). There were no significant interaction effects of genotype and condition on number of sniffs.

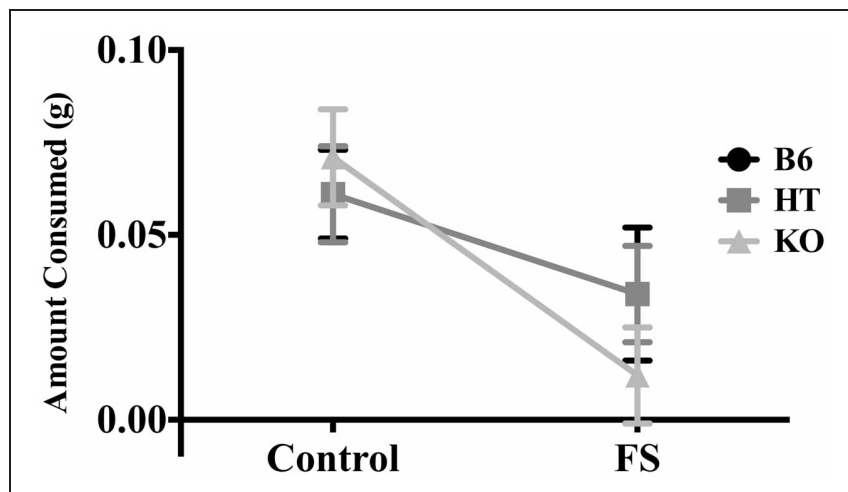

FIGURE 4 | Average amount of almond eaten during the 5-min NSF test by wild-type C57BL/6J (B6), heterozygous (HT), and $\beta$-E knock-out (KO) mice. Data show mean $\pm \mathrm{SE}$. ANOVA indicated that prior forced swim decreased consumption $(p \leq 0.05)$, but there were no differences between genotypes, nor was this effect dependent upon genotype.

mice were first exposed to FS in a genotype-dependent manner. (Figures 1,2). These data are in line with previous reports showing increased hyponeophagia in rodents exposed to unpredictable chronic mild stress (Bessa et al., 2009) or social isolation (Voikar et al., 2005), and extend these findings by suggesting a critical role for $\beta$-E.

The main effect of genotype on number of sniffs (Figure 3) suggests a direct relationship between peptide levels and interaction with the novel food stimulus. However, there was also an interaction between genotype and stress for latency to approach the almond (Figure 1) and whether the almond was approached (Figure 2); mice with lower levels of $\beta$-E displayed a stronger aversion to novelty-feeding after exposure to stress than did mice with higher levels. Moreover, there were no differences between wild-type (B6), HT, or, $\beta$-E knock-out (KO) mice under control conditions. Because the effects of stress on hyponeophagia are magnified with lower levels of $\beta-\mathrm{E}$, these data suggest that $\beta$-E plays an active role in coping behavior by mitigating the behavioral response to stress.

As expected based on pilot testing, there were no effects of or interactions between genotype and sex on immobile behavior of mice during the $3 \mathrm{~min}$ FS. In a previous study in our lab, using the same three strains of mice, we found effects of sex and genotype on immobility during a 15 min FS Test (Barfield et al., 2010). However, for the present study, we aimed to induce a subthreshold amount of stress that would not produce genotypic or sex differences in behavior during the FS so as to minimize the possibility that behavior in the NSF test would be confounded by factors such as fatigue from the FS. We found that $3 \mathrm{~min}$ of exposure to the FST was just stressful enough for genotypic differences in novelty-feeding to emerge. Furthermore, although we found an interaction between genotype and stress for latency to approach the almond and whether or not the almond was approached, there was no such interaction for number of sniffs and amount of almond eaten. It is possible that interactions between genotype and stress for the latter two measures may emerge with FS times longer than $3 \mathrm{~min}$.

Likewise, although we found no effects of sex on behavior during the NSF test, it is possible that this design did not induce sufficient stressor intensity to allow for detection of sex differences. Thus, the present findings do not preclude the possibility of sex differences in coping behavior. Given that sex differences in the risk for and prevalence of stress-related disorders in humans are well-documented (Kessler et al., 1993; Zilberman et al., 2003; Marcus et al., 2005; Hasin et al., 2007), future research should aim to develop animal models that reflect such differences.

The findings presented here support our earlier findings using the plus maze, light-dark box (Grisel et al., 2008), FS Test, and tail suspension test (TST; Barfield et al., 2010), suggesting that $\beta$-E contributes to the ability to behaviorally manage stressful stimuli. For example, we have shown an inverse relationship between $\beta$-E levels and anxious behavior (as measured by percent of open arm entries and time spent in the open arms in the plus maze, and time spent in the light compartment of the light-dark box; Grisel et al., 2008). We have also shown a direct relationship between $\beta$-E levels and immobility in the FST and TST (Barfield et al., 2010). Because these tests subject mice to inescapable aversive situations, whereby failure to exhibit actions aimed at escape may represent an effective coping strategy, these results suggest that $\beta$-E facilitates coping behavior. The present study provides additional evidence to support this role of $\beta$-E by showing that under conditions of acute stress, mice alter their behavior in an anxiogenic situation to mitigate a deficiency in $\beta$-E. Moreover, these data extend our earlier findings to suggest that behavior becomes increasingly influenced by underlying neurobiology when an organism is exposed to stressors.

An interaction of both genetic predisposition and environmental stressors contributes to increased risk for developing stress-induced psychopathology (Danese, 2008; Bet et al., 2009). In line with this view, it is possible that an individual who produces lower than normal amounts of $\beta$-E may suffer from an overactive HPA axis and an impaired ability to effectively manage 
stressful stimuli (behaviorally and physiologically). These factors may render an individual particularly susceptible to the aversive effects of stress and to developing anxiety and depression. Indeed, evidence from studies utilizing selectively bred rodent lines suggests that individual differences in HPA activity and anxiety traits may contribute to differential susceptibility to stress. Rats with a behavioral profile characterized by high anxiety and low exploration are particularly vulnerable to developing depression-like behaviors and HPA axis hyper-reactivity when exposed to subchronic stress, while low anxiety rats are more resistant to the development of stress-induced depression-like behavior (Castro et al., 2012). Additionally, rats classified as low-responders to novelty (high anxiety) who are exposed to chronic mild stress exhibit increased latencies to approach and consume food in the NSF test, while the behavior of rats classified as high-responders to novelty (low anxiety) is unaffected by chronic stress (Stedenfeld et al., 2011). Chronically stressed low-responder rats also become anhedonic more rapidly and to a greater degree than chronically stressed high-responder rats (Stedenfeld et al., 2011).

The role of genetic factors in the etiology of MDD and anxiety disorders is well recognized (Unschuld et al., 2009; see Sullivan et al., 2000, for review), as heritability is estimated to be around 40\% for MDD (Kendler et al., 2006b), and 32\% for GAD; Hettema et al., 2001. At least in part because of the complexity of these disorders, candidate gene studies have not been able to unambiguously identify susceptibility genes (Levinson, 2006). Moreover, the high comorbidity of MDD and anxiety disorders (Gorman, 1996; Kessler et al., 1996, 2008; Kaufman and Charney, 2000; Hettema et al., 2003) suggests that risk factors for these disorders are not mutually exclusive (Krueger, 1999; Ohara et al., 1999; Vollebergh et al., 2001; Gorwood, 2004). Indeed, twin studies indicate significant overlap of genetic risk factors for depression and anxiety (Hettema et al., 2003; Kendler et al., 2007). In particular, it has been suggested that the genes influencing liability to MDD are the same as those influencing liability to GAD (Kendler et al., 1992b). Nevertheless, genome-wide association studies suggest that a large number of genes, each with a small effect, influence susceptibility to MDD, and there is overlap in genetic risk factors with GAD (Demirkan et al., 2011).

Because the ability to cope with stress is an important factor influencing susceptibility to stress-related disorders (Meng et al., 2011; Mahmoud et al., 2012), it is possible that shared liability genes for anxiety and depression influence stress reactivity (Kendler et al., 1991; Gorwood, 2004; Yu et al., 2012). Indeed, stress-induced activation of the HPA axis is moderately to highly heritable (Federenko et al., 2004). Healthy individuals with depressed first-degree relatives show a moderately elevated cortisol response following challenge with dexamethasone (DEX$\mathrm{CRH}$ test), though not as elevated as that of patients with MDD (Holsboer et al., 1995), and healthy individuals with diagnosed parental history of anxiety or depression show higher cortisol awakening levels than individuals without parental history (Vreeburg et al., 2010). Moreover, the response of the $\beta$-E system to acute stress exposure is also highly heritable (Dai et al., 2002, 2005 ), and genetic variation in the $\mu$-opioid receptor contributes to the differential response of the HPA axis to stress (Chong et al., 2006; Schwandt et al., 2011).
Although a compelling number of studies report evidence for dysregulation of the HPA axis in patients suffering from depression and anxiety (Young et al., 1991; Carroll et al., 2007; Lloyd and Nemeroff, 2011), the above findings suggest that a hyperactive HPA axis in normal individuals may represent a vulnerability marker for stress-related psychopathology. Because $\beta$-E plays a role in moderating the effects of stress (Amir, 1982; Yamada and Nabeshima, 1995) as well as termination of the stress response (Buckingham, 1986), individual differences in HPA axis activation and subsequent release of $\beta$-E may influence differential vulnerability to stress-induced changes in the coordination and dynamics of the stress response. Indeed, depressed patients show hypertrophy of the adrenal gland (Rubin et al., 1995), indicative of HPA hyperactivity, and mice with low or absent $\beta$-E have enlarged adrenal glands, suggesting chronic upregulation of the HPA axis with decreased $\beta$-E levels (Grisel et al., 2008).

The present study, along with earlier studies in our lab, provides evidence of a moderating effect of $\beta$-E on the behavioral response to stress (Grisel et al., 2008; Barfield et al., 2010), implicating a role for this peptide in coping behavior. In particular, we found an effect of interaction between genetic predisposition and environmental stressors on anxious behavior in mice. Behavioral differences between "genetically vulnerable" (low or absent $\beta$-E) and "genetically resistant" mice emerged when mice were exposed to a stressor before the NSF test. These data suggest that low $\beta$-E levels impair the ability to return to a basal state following stress exposure, and thus compromise coping ability. Considering the evidence for heritability of stress-induced HPA axis activity together with the findings presented here, it is possible that genetically determined differences in sensitivity of the $\beta$-E system to stress contribute, at least in part, to heritable differences in vulnerability to developing anxiety and depression (Charmandari et al., 2005; Hegadoren et al., 2009; Merenlender-Wagner et al., 2009).

MDD and anxiety disorders affect a significant portion of the nation, with a lifetime prevalence of $\sim 20 \%$ for MDD and $28 \%$ for anxiety disorders (Kessler et al., 2005). Although the neural mechanisms involved are poorly understood, evidence from clinical and pre-clinical studies implicates the role of HPA axis abnormalities in the pathophysiology of mood and anxiety disorders (Carroll et al., 2007; see Arborelius et al., 1999, for review). Thus, genetically mediated interindividual differences in HPA axis activity may help explain why some individuals are particularly vulnerable, and others resilient, to anxiety and depression (Holsboer et al., 1995; Wüst et al., 2000; McEwen, 2002; Vreeburg et al., 2010). Altogether, our findings suggest that $\beta$-E facilitates coping behavior. Low levels of this peptide may impair the coordination and dynamics of the stress response, thereby enhancing vulnerability to stress-related psychopathology. Further investigation of the role of $\beta$-E in allostasis of the stress response may yield insight into the etiology of anxiety and depression.

\section{ACKNOWLEDGMENTS}

This work was supported by NIH Grant AA13641 to Judith E. Grisel from the National Institute on Alcohol Abuse and Alcoholism. 


\section{REFERENCES}

Amir, S. (1982). Involvement of endogenous opioids with forced swimming-induced immobility in mice. Physiol. Behav. 28, 249-251.

Arborelius, L., Owens, M. J., Plotsky, P. M., and Nemeroff, C. B. (1999). The role of corticotropin-releasing factor in depression and anxiety disorders. J. Endocrinol. 160, 1-12.

Barfield, E. T., Barry, S. M., Hodgin, H. B., Thompson, B. M., Allen, S. A., and Grisel, J. E. (2010). $\beta$-endorphin mediates behavioral despair and the effect of ethanol on the tail suspension test in mice. Alcohol. Clin. Exp. Res. 34, 1066-1072.

Bessa, J. M., Mesquita, A. R., Oliveira, M., Pêgo, J. M., Cerqueira, J. J., Palha, J. A., et al. (2009). A trans-dimensional approach to the behavioral aspects of depression. Front. Behav. Neurosci. 3:1. doi: 10.3389/neuro.08.001.2009

Bet, P. M., Penninx, B. W., Bochdanovits, Z., Uitterlinden, A. G., Beekman, A. T., van Schoor, N. M., et al. (2009). Glucocorticoid receptor gene polymorphisms and childhood adversity are associated with depression: new evidence for a gene-environment interaction. Am. J. Med. Genet. B Neuropsychiatr. Genet. 150B, 660-669.

Bodnar, R. J., Kelly, D. D., Brutus, M., and Glusman, M. (1980). Stressinduced analgesia: neural and hormonal determinants. Neurosci. Biobehav. Rev. 4, 87-100.

Bodnoff, S. R., Suranyi-Cadotte, B., Aitken, D. H., Quirion, R., and Meaney, M. J. (1988). The effects of chronic antidepressant treatment in an animal model of anxiety. Psychopharmacology (Berl.) 95, 298-302.

Branchi, I., and Ricceri, L. (2002). Transgenic and knock-out mouse pups: the growing need for behavioral analysis. Genes Brain Behav. 1, 135-141.

Britton, D. R., and Britton, K. T. (1981). A sensitive open field measure of anxiolytic drug activity. Pharmacol. Biochem. Behav. 15, 577-582.

Brown, G. W., Bifulco, A., and Harris, T. O. (1987). Life events, vulnerability and onset of depression: some refinements. Br. J. Psychiatry 150, 30-42.

Buckingham, J. C. (1986). Stimulation and inhibition of corticotrophin releasing factor secretion by endorphin. Neuroendocrinology 42, 148-152.

Carroll, B. J., Cassidy, F., Naftolowitz, D., Tatham, N. E., Wilson, W. H., Iranmanesh, A., et al. (2007). Pathophysiology of hypercortisolism in depression.
Acta Pschiatr. Scand. Suppl. 433, 90-103.

Carver, C. S., and Connor-Smith, J. (2010). Personality and coping. Annu. Rev. Psychol. 61, 679-704.

Castro, J. E., Diessler, S., Varea, E., Márquez, C., Larsen, M. H., Cordero, M. I., et al. (2012). Personality traits in rats predict vulnerability and resilience to developing stress-induced depression-like behaviors, HPA axis hyper-reactivity and brain changes in pERK1/2 activity. Psychoneuroendocrinology 37, 1209-1223.

Charmandari, E., Tsigos, C., and Chrousos, G. (2005). Endocrinology of the stress response. Annu. Rev. Physiol. 67, 259-284.

Chong, R. Y., Oswald, L., Yang, X., Uhart, M., Lin, P. I., and Wand, G. S. (2006). The mu-opioid receptor polymorphism A118G predicts cortisol responses to naloxone and stress. Neuropsychopharmacology 31, 204-211.

Cryan, J. F., and Sweeney, F. F. (2011). The age of anxiety: role of animal models of anxiolytic action in drug discovery. Br. J. Pharmacol. 164, 1129-1161.

Dai, X., Thavundayil, J., and Gianoulakis, C. (2002). Differences in the responses of the pituitary beta-endorphin and cardiovascular system to ethanol and stress as a function of family history. Alcohol. Clin. Exp. Res. 26, 1171-1180.

Dai, X., Thavundayil, J., and Gianoulakis, C. (2005). Differences in the peripheral levels of betaendorphin in response to alcohol and stress as a function of alcohol dependence and family history of alcoholism. Alcohol. Clin. Exp. Res. 29, 1965-1975.

Danese, A. (2008). Genetic opportunities for psychiatric epidemiology: on life stress and depression. Epidemiol. Psichiatr. Soc. 17, 201-210.

Demirkan, A., Penninx, B. W., Hek, K., Wray, N. R., Amin, N., Aulchenko, Y. S., et al. (2011). Genetic risk profiles for depression and anxiety in adult and elderly cohorts. Mol. Psychiatry 16, 773-783.

de Rijk, R., and de Kloet, E. R. (2005). Corticosteroid receptor genetic polymorphisms and stress responsivity. Endocrine 28, 263-270.

Feder, A., Nestler, E. J., and Charney, D. S. (2009). Psychobiology and molecular genetics of resilience. Nat. Rev. Neurosci. 10, 446-457.

Federenko, I. S., Nagamine, M., Hellhammer, D. H., Wadhwa, P. D., and Wüst, S. (2004). The heritability of hypothalamus pituitary adrenal axis responses to psychosocial stress is context dependent. J. Clin. Endocrinol. Metab. 89, 6244-6250.

Gianoulakis, C. (1998). Alcoholseeking behavior: the roles of the hypothalamic-pituitaryadrenal axis and the endogenous opioid system. Alcohol. Health Res. World 22, 202-210.

Gorman, J. M. (1996). Comorbid depression and anxiety spectrum disorders. Depress. Anxiety 4, 160-168.

Gorwood, P. (2004). Generalized anxiety disorder and major depressive disorder comorbidity: an example of genetic pleiotropy? Eur. Psychiatry 19, 27-33.

Grisel, J. E., Bartels, J. L., Allen, S. A., and Turgeon, V. L. (2008). Influence of $\beta$-endorphin on anxious behavior in mice: interaction with $\mathrm{EtOH}$. Psychopharmacology 200, 105-115.

Hammen, C., Davila, J., Brown, G. Ellicott, A., and Gitlin, M. (1992). Psychiatric history and stress: predictors of severity of unipolar depression. J. Abnorm. Psychol. 101, 45-52.

Hasin, D. S., Stinson, F. S., Ogburn, E., and Grant, B. F. (2007). Prevalence, correlates, disability, and comorbidity of DSM-IV alcohol abuse and dependence in the United States: results from the National Epidemiologic Survey on Alcohol and Related Conditions. Arch. Gen. Psychiatry 64, 830-842.

Hegadoren, K. M., O’Donnell, T., Lanius, R., Coupland, N. J., and Lacaze-Masmonteil, N. (2009). The role of beta-endorphin in the pathophysiology of major depression. Neuropeptides 43, 341-353.

Hettema, J. M., Neale, M. C., and Kendler, K. S. (2001). A review and meta-analysis of the genetic epidemiology of anxiety disorders. Am. J. Psychiatry 158, 1568-1578.

Hettema, J. M., Prescott, C. A., and Kendler, K. S. (2003). The effects of anxiety, substance abuse and conduct disorders on risk of major depressive disorder. Psychol. Med. 33, 1423-1432.

Holsboer, F., Lauer, C. J., Schreiber, W., and Krieg, J.-C. (1995). Altered hypothalamic-pituitaryadrenocortical regulation in healthy subjects at high familial risk for affective disorders. Neuroendocrinology 62, 340-347.

Hossain, S. M., Wong, B. K., and Simpson, E. M. (2004). The dark phase improves genetic discrimination for some high throughput mouse behavioral testing. Genes Brain Behav. 3, 167-177.

Kaufman, J., and Charney, D. (2000). Comorbidity of mood and anxiety disorders. Depress. Anxiety 12(Suppl. 1), 69-76.

Kendler, K. S., Gardner, C. O., Gatz, M., and Pedersen, N. L. (2007). The sources of co-morbidity between major depression and generalized anxiety disorder in a Swedish national twin sample. Psychol. Med. 37, 453-462.

Kendler, K. S., Gatz, M., Gardner, C. O., and Pedersen, N. L. (2006a). Personality and major depression: a Swedish longitudinal, populationbased twin study. Arch. Gen. Psychiatry 63, 1113-1120.

Kendler, K. S., Gatz, M., Gardner, C. O., and Pedersen, N. L. (2006b). A Swedish national twin study of lifetime major depression. Am. J. Psychiatry 163, 109-114.

Kendler, K. S., Kessler, R. C., Heath, A. C., Neale, M. C., and Eaves, L. J. (1991). Coping: a genetic epidemiological investigation. Psychol. Med. 21, 337-346.

Kendler, K. S., Neale, M. C., Kessler, R. C., Heath, A. C., and Eaves, L. J. (1992a). Childhood parental loss and adult psychopathology in women. Arch. Gen. Psychiatry 49, 109-116.

Kendler, K. S., Neale, M. C., Kessler, R. C., Heath, A. C., and Eaves, L. J. (1992b). Major depression and generalized anxiety disorder. Same genes, (partly) different environments? Arch. Gen. Psychiatry 49, 716-722.

Kessler, R. C., Berglund, P., Demler, O., Jin, R., Merikangas, K. R., and Walters, E. E. (2005). Lifetime prevalence and age-of-onset distributions of DSM-IV disorders in the national comorbidity survey replication. Arch. Gen. Psychiatry 62, 593-602.

Kessler, R. C., Gruber, M., Hettema, J. M., Hwang, I., Sampson, N., and Yonkers, K. A. (2008). Comorbid major depression and generalized anxiety disorders in the national comorbidity survey follow-up. Psychol. Med. 38, 365-374.

Kessler, R. C., McGonagle, K. A., Swartz, M., Blazer, D. G., and Nelson, C. B. (1993). Sex and depression in the National Comorbidity Survey. I: lifetime prevalence, chronicity and recurrence. J. Affect. Disord. 29, 85-96.

Kessler, R. C., Nelson, C. B., McGonagle, K. A., Liu, J., Swartz, M., and Blazer, D. G. (1996). Comorbidity of DSM-III-R major depressive disorder in the general population: results from the US national comorbidity survey. $\mathrm{Br}$. J. Psychiatry Suppl. 17-30. 
Krueger, R. F. (1999). The structure of common mental disorders. Arch. Gen. Psychiatry 56, 921-926.

Lee-Bagley, D., Preece, M., and DeLongis, A. (2005). Coping with interpersonal stress: role of big five traits. J. Pers. 73, 1141-1180.

LeSauter, J., Hoque, N., Weintraub, M., Pfaff, D. W., and Silver, R. (2009). Stomach ghrelin-secreting cells as food-entrainable circadian clocks. Proc. Natl. Acad. Sci. U.S.A. 106, 13582-13587.

Levinson, D. F. (2006). The genetics of depression: a review. Biol. Psychiatry 60, 84-92.

Lloyd, R. B., and Nemeroff, C. B. (2011). The role of corticotropinreleasing hormone in the pathophysiology of depression: therapeutic implications. Curr. Top. Med. Chem. 11, 609-617.

Low, M. J. (2004). Role of proopiomelanocortin neurons and peptides in the regulation of energy homeostasis. J. Endocrinol. Invest. 27(6 Suppl.), 95-100.

Mahmoud, J. S., Staten, R., Hall, L. A., and Lennie, T. A. (2012). The relationship among young adult college students' depression, anxiety, stress, demographics, life satisfaction, and coping styles. Issues Ment. Health Nurs. 33, 149-156.

Marcus, S. M., Young, E. A., Kerber, K. B., Kornstein, S., Farabaugh, A. H., Mitchell, J., et al. (2005). Gender differences in depression: findings from the $\mathrm{STAR}^{\star} \mathrm{D}$ study. J. Affect. Disord. 87, 141-150.

McEwen, B. S. (2002). Sex, stress and the hippocampus: allostasis, allostatic load and the aging process. Neurobiol. Aging 23, 921-939.

McEwen, B. S. (2003). Early life influences on life-long patterns of behavior and health. Ment. Retard. Dev. Disabil. Res. Rev. 9, 149-154.

Meng, X. H., Tao, F. B., Wan, Y. H., Hu, Y., and Wang, R. X. (2011). Coping as a mechanism linking stressful life events and mental health problems in adolescents. Biomed. Environ. Sci. 24, 649-655.

Merali, Z., Levac, C., and Anisman, H. (2003). Validation of a simple, ethologically relevant paradigm for assessing anxiety in mice. Biol. Psychiatry 54, 552-565.

Merenlender-Wagner, A., Dikshtein, Y., and Yadid, G. (2009). The betaendorphin role in stress-related psychiatric disorders. Curr. Drug Targets 10, 1096-1108.

Nakagawasai, O., Tadano, T., Tan No, K., Niijima, F., Sakurada, S., Endo, Y., et al. (1999). Changes in betaendorphin and stress-induced analgesia in mice after exposure to forced walking stress. Methods Find. Exp. Clin. Pharmacol. 21, 471-476.

Ohara, K., Suzuki, Y., Ochiai, M., Tsukamoto, T., Tani, K., and Ohara, K. (1999). A variable-numbertandem-repeat of the serotonin transporter gene and anxiety disorders. Prog. Neuropsychopharmacol. Biol. Psychiatry 23, 55-65.

Parikh, D., Hamid, A., Friedman, T. C., Nguyen, K., Tseng, A., Marquez, P., et al. (2011). Stress-induced analgesia and endogenous opioid peptides: the importance of stress duration. Eur. J. Pharmacol. 650, 563-567.

Plotsky, P. M. (1991). Pathways to the secretion of adrenocorticotropin: a review from the portal. J. Endocrinol. 3, 1-18.

Porsolt, R. D., le Pichon, M., and Jalfre, M. (1977). Depression: a new animal model sensitive to antidepressant treatments. Nature 266, 730-732.

Ribeiro, S. C., Kennedy, S. E., Smith, Y. R., Stohler, C. S., and Zubieta, J. K. (2005). Interface of physical and emotional stress regulation through the endogenous opioid system and mu-opioid receptors. Prog. Neuropsychopharmacol. Biol. Psychiatry 29, 1264-1280.

Roedel, A., Storch, C., Holsboer, F., and Ohl, F. (2006). Effects of light or dark phase testing on behavioral and cognitive performance in DBA mice. Lab. Anim. 40, 371-381.

Rubin, R. T., Phillips, J. J., Sadow, T. F., and McCracken, J. T. (1995). Adrenal gland volume in major depression. Increase during the depressive episode and decrease with successful treatment. Arch. Gen. Psychiatry 52, 213-218.

Rubinstein, M., Mogil, J. S., Japón, M., Chan, E. C., Allen, R. G., and Low, M. J. (1996). Absence of opioid stress-induced analgesia in mice lacking $\beta$-endorphin by sitedirected mutagenesis. Proc. Natl. Acad. Sci. U.S.A. 93, 3995-4000.

Sandi, C., Cordero, M. I., Ugolini, A., Varea, E., Caberlotto, L., and Large, C. H. (2008). Chronic stressinduced alterations in amygdala responsiveness and behaviormodulation by trait anxiety and corticotropin-releasing factor systems. Eur. J. Neurosci. 28, 1836-1848.

Sandi, C., and Richter-Levin, G. (2009). From high anxiety trait to depression: a neurocognitive hypothesis. Trends Neurosci. 32, 312-320.

Sarkar, D. K., Kuhn, P., Marano, J., Chen, C., and Boyadjieva, N. (2007). Alcohol exposure during the developmental period induces beta-endorphin neuronal death and causes alteration in the opioid control of stress axis function. Endocrinology 148, 2828-2834.

Schedlowski, M., Flüge, T., Richter, S., Tewes, U., Schmidt, R. E. and Wagner, T. O. (1995). Betaendorphin, but not substance-P, is increased by acute stress in humans. Psychoneuroendocrinology 20, 103-110.

Schwandt, M. L., Lindell, S. G., Higley, J. D., Suomi, S. J., Heilig, M., and Barr, C. S. (2011). OPRM1 gene variation influences hypothalamicpituitary-adrenal axis function in response to a variety of stressors in rhesus macaques. Psychoneuroendocrinology 36, 1303-1311.

Shephard, R. A., Hewitt, J. K., and Broadhurst, P. L. (1985). The genetic architecture of hyponeophagia and the action of diazepam in rats. Behav. Genet. 15, 265-286.

Southwick, S. M., Vythilingam, M., and Charney, D. S. (2005). The psychobiology of depression and resilience to stress: implications for prevention and treatment. Annu. Rev. Clin. Psychol. 1, 255-291.

Stedenfeld, K. A., Clinton, S. M. Kerman, I. A., Akil, H., Watson, S. J., and Sved, A. F. (2011). Noveltyseeking behavior predicts vulnerability in a rodent model of depression. Physiol. Behav. 103, 210-216.

Stiller, A. L., Drugan, R. C., Hazi, A., and Kent, S. P. (2011). Stress resilience and vulnerability: the association with rearing conditions, endocrine function, immunology, and anxious behavior. Psychoneuroendocrinology 36, 1383-1395.

Sullivan, P. F., Neale, M. C., and Kendler, K. S. (2000). Genetic epidemiology of major depression: review and meta-analysis. Am. J. Psychiatry 157, 1552-1562.

Unschuld, P. G., Ising, M., Specht, M., Erhardt, A., Ripke, S., Heck, A., et al. (2009). Polymorphisms in the GAD2 gene-region are associated with susceptibility for unipolar depression and with a risk factor for anxiety disorders. Am. J. Med. Genet. B Neuropsychiatr. Genet. 150B, 1100-1109.

van Santen, A., Vreeburg, S. A., Van der Does, A. J., Spinhoven, P. Zitman, F. G., and Penninx, B. W. (2011). Psychological traits and the cortisol awakening response: results from the Netherlands study of depression and anxiety. Psychoneuroendocrinology 36, 240-248.

Vreeburg, S. A., Hartman, C. A., Hoogendijk, W. J., van Dyck, R., Zitman, F. G., Ormel, J., et al. (2010). Parental history of depression or anxiety and the cortisol awakening response. $\mathrm{Br}$. J. Psychiatry 197, 180-185.

Voikar, V., Polus, A., Vasar, E., and Rauvala, H. (2005). Long-term individual housing in $\mathrm{C} 57 \mathrm{BL} / 6 \mathrm{~J}$ and DBA/2 mice: assessment of behavioral consequences. Genes Brain Behav. 4, 240-252.

Vollebergh, W. A., Iedema, J., Bijl R. V., de Graaf, R., and Ormel, J. (2001). The structure and stability of common mental disorders: the NEMESIS study. Arch. Gen. Psychiatry 58, 597-603.

Wüst, S., Federenko, I., Hellhammer, D. H., and Kirschbaum, C. (2000). Genetic factors, perceived chronic stress, and the free cortisol response to awakening. Psychoneuroendocrinology 25, 707-720.

Yamada, K., and Nabeshima, T. (1995). Stress-induced behavioral responses and multiple opioid systems in the brain. Behav. Brain Res. 67, 133-145.

Young, E. A., Haskett, R. F., MurphyWeinberg, V., Watson, S. J., and Akil, H. (1991). Loss of glucocorticoid fast feedback in depression. Arch. Gen. Psychiatry 48, 693-699.

Yu, H., Wang, D. D., Wang, Y., Liu, T., Lee, F. S., and Chen, Z. Y. (2012). Variant brain-derived neurotrophic factor Val66Met polymorphism alters vulnerability to stress and response to antidepressants. J. Neurosci. 32, 4092-4101.

Zilberman, M. L., Tavares, H., Blume, S. B., and el-Guebaly, N. (2003). Substance use disorders: sex differences and psychiatric comorbidities. Can. J. Psychiatry 48, 5-13.

Conflict of Interest Statement: The authors declare that the research was conducted in the absence of any commercial or financial relationships that could be construed as a potential conflict of interest.

Received: 31 October 2012; accepted: 26 February 2013; published online: 14 March 2013.

Citation: Barfield ET, Moser VA, Hand $A$ and Grisel JE (2013) $\beta$-endorphin modulates the effect of stress on noveltysuppressed feeding. Front. Behav. Neurosci. 7:19. doi: 10.3389/fnbeh. 2013.00019

Copyright () 2013 Barfield, Moser, Hand and Grisel. This is an openaccess article distributed under the terms of the Creative Commons Attribution License, which permits use, distribution and reproduction in other forums, provided the original authors and source are credited and subject to any copyright notices concerning any third-party graphics etc. 